\title{
Analysis of Selected Properties of Fibreboard Panels Manufactured from Wood and Leather Using the Near Infrared Spectroscopy
}

\author{
Kerstin Wagner, ${ }^{1}$ Thomas Schnabel, ${ }^{1}$ \\ Marius-Catalin Barbu, ${ }^{1,2}$ and Alexander Petutschnigg ${ }^{1,3}$ \\ ${ }^{1}$ Department of Forest Products Technology and Timber Constructions, Salzburg University of Applied Sciences, \\ Markt 136a, 5431 Kuchl, Austria \\ ${ }^{2}$ Faculty of Wood Engineering, "Transilvania" University of Brasov, Strada Universitatii, No. 1, 500068 Brasov, Romania \\ ${ }^{3}$ BOKU University of Natural Resources and Life Sciences, Konrad Lorenzstraße 24, 3430 Tulln, Austria
}

Correspondence should be addressed to Kerstin Wagner; kerstin.wagner@fh-salzburg.ac.at

Received 30 October 2015; Accepted 9 December 2015

Academic Editor: Hicham Fenniri

Copyright (C) 2015 Kerstin Wagner et al. This is an open access article distributed under the Creative Commons Attribution License, which permits unrestricted use, distribution, and reproduction in any medium, provided the original work is properly cited.

\begin{abstract}
This paper deals with the characterization of the properties of wood fibres leather shavings composite board by using the near infrared spectroscopy (NIRS) and multivariate data analysis. In this study fibreboards were manufactured with different leather amounts by using spruce fibres, as well as vegetable and mineral tanned leather shavings (wet white and wet blue). The NIR spectroscopy was used to analyse the raw materials as well as the wood leather fibreboards. Moreover, the physical and mechanical features of the wood leather composite fibreboards were determined to characterize their properties for the further data analysis. The NIR spectra were analysed by univariate and multivariate methods using the Principal Component Analysis (PCA) and the Partial Least Squares Regression (PLSR) method. These results demonstrate the potential of FT-NIR spectroscopy to estimate the physical and mechanical properties (e.g., bending strength). This phenomenon provides a possibility for quality assurance systems by using the NIRS.
\end{abstract}

\section{Introduction}

The scarcity of resources can be a motor or motivation for innovation. The application of unused biogenic resources is one way where innovation can happen. With these new raw materials the product characteristics can change; thus material analysis and material test are necessary to determine the composite properties. Also guidelines for quality assurance of the new materials can aid in the transfer from laboratory to industrial conditions for consumer applications.

There is a lot of innovation regarding the use of byproduct from biogenic resources in the forest product field [1]. Most of these investigations were dealing with an up- or recycling of by-products to find possible supplements to the fibres and particles for wood based panel production $[2,3]$. Han et al. [4] and Halvarsson et al. [5, 6] produced fibreboards from wheat and reed remains in combination with urea formaldehyde (UF) and urea melamine formaldehyde (UMF) adhesives. Also, exotic materials such as coconut fibres [7, 8], steam exploded banana bunch fibres [9], and bamboo and rice straw [10] were investigated mechanically as well as physically and obtained meaningful insights into possible alternatives to conventionally produced fibreboards and particleboards. Kargarfard et al. [11] investigated encouraging agrobased materials as cotton and corn stalks in MDF. Lee [12] combined bagasse with other biobased materials, as bamboo, in particleboards and analysed their mechanical and physical properties.

Besides the biobased materials also the fossil-based materials, such as plastic waste [2], were examined in combination with wood particles and fibres, and its degradability was determined. A seminal way to upcycling by-products seems 


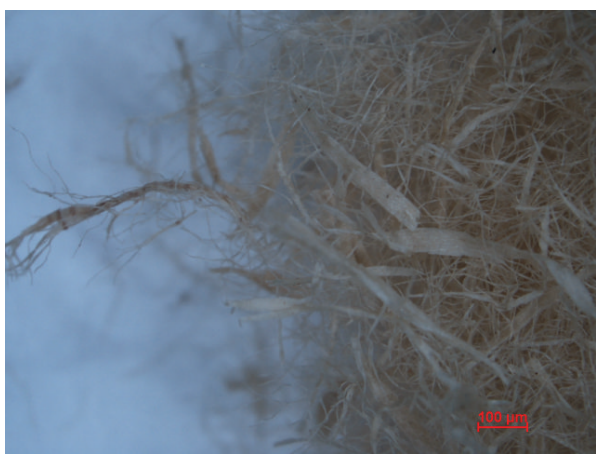

(a)

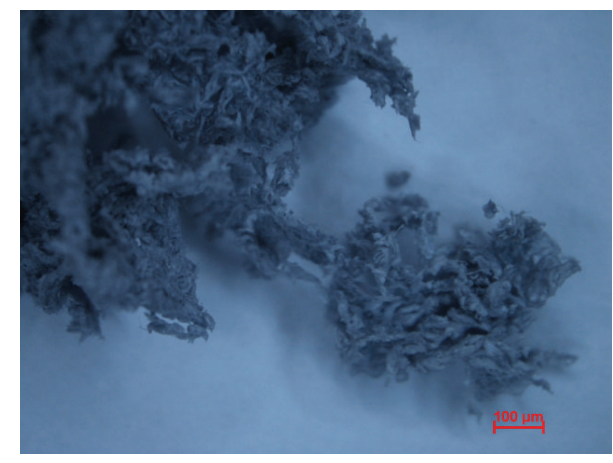

(b)

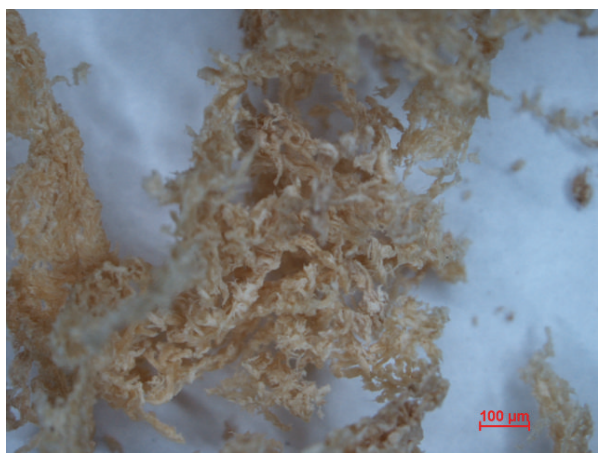

(c)

FIGURE 1: Raw materials to produce the composite materials: (a) wood fibres, (b) leather shavings wet blue, and (c) leather shavings wet white.

to be the usage of waste materials, such as chicken feathers and leather shavings, which occur in the meat industry [13, 14]. Also, in the leather and tannery industry, a huge amount of waste incurs every year, alone in Europe more than 200000 tons a year [15]. This waste is then disposed together with other urban wastes [16].

To produce a wood based panel out of a mixture of wood fibres and leather particles is a quite new idea, which was patented by Lackinger [17] in the year 2009. Investigations by Rindler et al. [18], Solt et al. [19, 20], and Wieland et al. [21] describe the mechanical and physical properties of leather shavings in MDF. A multitude of fibreboards with different percentages of leather shavings and wood fibres were tested to analyse the influence on the leather of the mechanical properties (e.g., internal bond). The behaviour can be explained with the structural and the chemical properties of the various materials. Differences in functional groups of leather, wood, and adhesion were analysed by ${ }^{13} \mathrm{C}-\mathrm{NMR}$ [22], Raman spectroscopy [23], and FT-IR spectroscopy [24]. Moreover, the NIR spectroscopy in combination with multivariate data analysis was applied in the wood industry for a quality assurance control system [25]. Also detailed information about the application of NIR spectroscopy in wood and paper research is given by Tsuchikawa [26].

Therefore, based on their mechanical and technical properties the wood leather fibre composites are one of the most interesting wood engineered materials of the last years. These composite materials are highly sustainable because they can be produced by coupling wood fibres with industrial waste of tannery plants. The analysis of the wood leather fibreboard with the near infrared spectroscopy (NIRS) can provide a basis for further efforts in the upscaling from the laboratory to industrial conditions for consumer application concerning this tool for the development of quality assurance control system.

\section{Experimental}

2.1. Material. When leather gets produced, hides have to run through different production steps. After the withdrawal of the skin a preservation process has to be done to protect the freshly peeled skins against the influence of microorganisms. The next step, the tanning process, is used to protect the skin against enzymatic degradation and increase their resilience. Only after this production step the skins are called leather. For this investigation the leather types, wet blue and wet white, were used (Figure 1).

The leather particles accrue during the shaving process of hides preparation, where they got sliced to a specific thickness. These particles were dried to moisture content (m.c.) of $8 \pm 1 \%$ in a small size dry kiln (Brunner-Hildebrand) of Salzburg University of Applied Sciences at Campus Kuchl at a temperature of $40^{\circ} \mathrm{C}$.

Norway spruce wood fibres (Picea abies (L.) [Karst.]) were used for this study. The fibres were produced in an industrial facility for MDF production and were unglued with an m.c. of $8 \pm 1 \%$. 


\subsection{Method}

2.2.1. Fibreboard Manufacturing. The spruce fibres and wet white leather particles were glued based on the oven-dry density with $10 \%$ urea formaldehyde (UF) resin with $1 \%$ ammonium sulphate solution in a lab ENT WBH 75 ploughshare blender type with a Schlick two-substance nozzle upright section. For the process a nozzle with a whole diameter of $2.3 \mathrm{~mm}$ and a pneumatic pressure of 2 bar was used. Further the glued fibres were distributed manually in a frame and were pressed to a final thickness of 8 to $20 \mathrm{~mm}$ in a Hoefer HLPO 280 automated hot lab press at $80^{\circ} \mathrm{C}$ with a pressing factor of $1 \mathrm{~min} / \mathrm{mm}$. Fibreboards with dimensions of $450 \times$ $450 \mathrm{~mm}^{2}$ with different thicknesses were produced under laboratory conditions. The ratio of different leathers to the wood fibres and the various thickness of fibreboard samples were selected from the results of various previous mechanical studies by Solt et al. $[18,19]$. After the pressing process the samples were stored in a standard climate $\left(20^{\circ} \mathrm{C} / 65 \%\right.$ r.H $)$.

\subsubsection{FT-NIR Spectroscopy. For FT-NIR measurements each} raw material (e.g., leather particles and wood fibres) was milled with a cutting mill (Retsch) using solid $\mathrm{CO}_{2}$ to pass a mesh of $500 \mu \mathrm{m}$ and the fractions between 250 and $63 \mu \mathrm{m}$ were separated with a sieving apparatus (Retsch). Then the powder was dried at $50^{\circ} \mathrm{C}$ for one week.

The FT-NIR spectra were obtained on the surface of wood leather fibreboards and on the milled fibres of each sample by an MPA spectrometer (Buker) equipped with a fibre probe $\left(4 \mathrm{~mm}\right.$ measurement diameter) at a resolution of $8 \mathrm{~cm}^{-1}(32$ scans). For every wood leather fibreboard and milled fibres five single spectra of the surface per sample were taken to minimize the influence of different concentrations of wood and leather shavings on various wood leather panels.

2.2.3. Mechanical Testing Methods. The sample preparation and the mechanical testing procedure for the modulus of rupture (MOR) and elasticity (MOE) were done according to the OENORM EN 326-1 [27] and the OENORM EN 310 [28]. To obtain meaningful results, each of the mechanical tests had an amount of 5 samples.

2.2.4. Data Analysis. The Unscrambler 10.3 software (CAMO, Norway) was used for the data analysis. The FT-NIR spectra were managed without data treatment and also were pretreated by using the second derivative (15 smoothing points). Principal Component Analysis (PCA) is a linear projection method to reduce the multidimensional data (e.g., NIR spectra) to only few orthogonal features (principal components (PCs)). The Partial Least Squares Regression (PLSR) method was applied to find the latent variables in $X$ (e.g., NIR spectra) that would best describe the variables in $Y$ (e.g., bending strength). Esbensen [29] and Kessler [30] give detailed information about the PLSR method. On one hand the NIR spectra were not pretreated. On the other hand the NIR spectra were pretreated by using the second derivative ( 15 smoothing points). The NIR data sets of various wood leather panels were regressed versus different physical

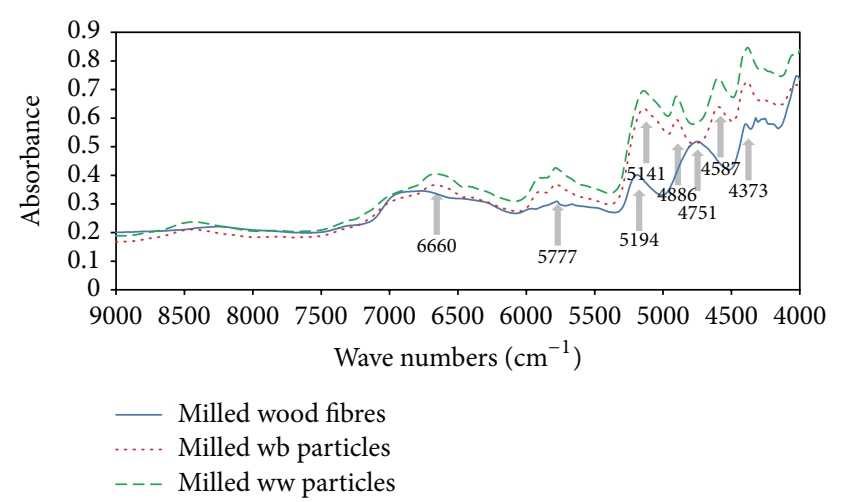

FIGURE 2: FT-NIR spectra of various raw materials in the wave number range of $9000-4000 \mathrm{~cm}^{-1}$.

and mechanical properties of the cross-validation (root mean square error of cross-validation [RMSECV]) of the models.

\section{Results and Discussion}

The chemical information relating to the two different milled leather powders and the milled wood powder was obtained by using the FT-NIR spectroscopy. Figure 2 shows the spectra in the region between the wave number range $9000-4000 \mathrm{~cm}^{-1}$ of the wood fibres and the wet white (ww) and the wet blue (wb) leather fibres. The differences between the wood fibres spectrum and the leather fibres spectra can be observed. The bands around the wave numbers 6660,4886 , and $4587 \mathrm{~cm}^{-1}$ corresponded with the structure of proteins, here especially the first overtone of $\mathrm{N}-\mathrm{H}$ stretching, the single or combination of amide I or amide II, and the second overtone of N$\mathrm{H}$ bending vibrations [31]. Also the second overtone of $\mathrm{O}-\mathrm{H}$ bending vibrations at band around $5141 \mathrm{~cm}^{-1}$ [31] is different compared to the wood fibres spectrum as this spectrum shows the first overtone $\mathrm{O}-\mathrm{H}$ stretching vibrations at the wave number $5192 \mathrm{~cm}^{-1}$ [32]. Furthermore, the spectrum of the wood fibres shows a significant difference at the band around $4751 \mathrm{~cm}^{-1}$, which corresponded to the third overtone of the asymmetric $\mathrm{C}-\mathrm{O}-\mathrm{O}$ stretching and the $\mathrm{O}-\mathrm{H}$ bending as well as the $\mathrm{C}-\mathrm{O}$ stretching vibrations $[31,32]$. The bands at around 5777 and $4373 \mathrm{~cm}^{-1}$ corresponded to the first overtone of C$\mathrm{H}$ stretching and the second overtone of $\mathrm{C}-\mathrm{H}$ bending as well as $\mathrm{CH}_{2}$ deformation vibrations [31].

These results show that the NIR spectroscopy is suitable for characterizing different materials of wood and leather, which was also depicted by the FT-IR and Raman Spectroscopy $[23,24]$. However, the two types of leather fibres cannot be distinguished by the NIR spectra analysis.

Also, the NIR spectra of the various wood leather panels show differences in IR bands (Figure 3). The significant bands are around the wave numbers 4886 and $4587 \mathrm{~cm}^{-1}$ for the leather particles and the wave number $4751 \mathrm{~cm}^{-1}$ for the wood fibres. With the increase of the amount of ww leather shavings the changes in these wave numbers can be observed. Further analysis should be done to show the potential of NIRS for the classification of the leather and wood fibre amount in 


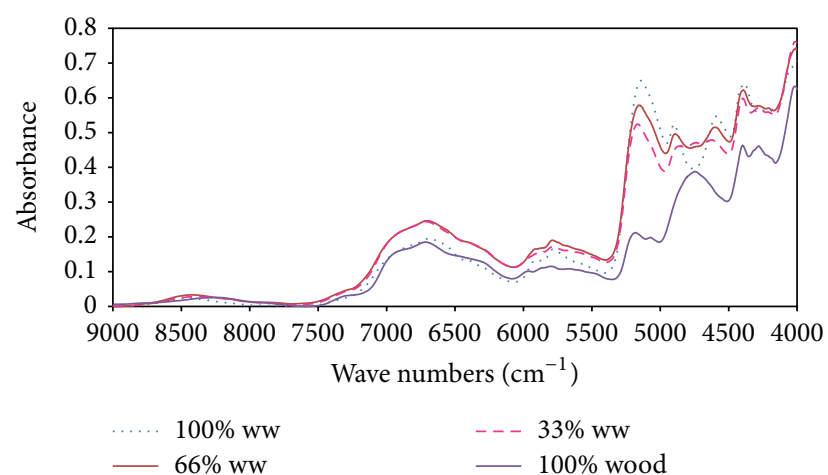

FIGURE 3: FT-NIR spectra of wood leather fibreboards with various concentrations of wood and wet white ( $\mathrm{ww}$ ) leather particles in the wave number range between 9000 and $4000 \mathrm{~cm}^{-1}$.

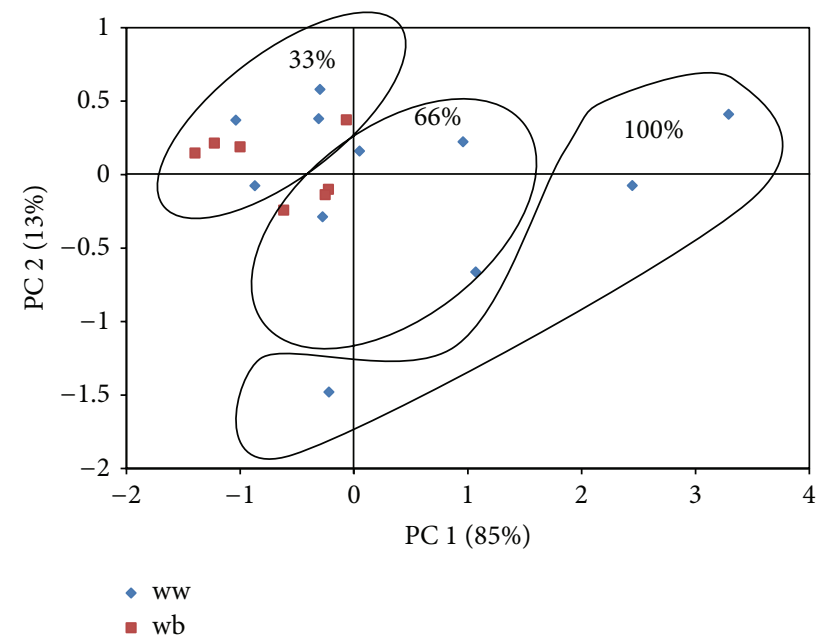

FIgURE 4: Principal component (PC) analysis score plot of near infrared spectra of various wood fibre leather panels.

various panels. However, both types of leather shavings ww and $\mathrm{wb}$ were together analysed because of the insignificant differences in the NIR spectra.

For this reason, the data of the NIRS were used for the classification via principal components analysis (PCA). Figure 4 states the distribution of the measurements for the wood leather panels. Also, in this case, the variance of the data explained by the PC is reported in parentheses.

It can be observed that the two principal components allow the classification of the amount of leather shavings in the panels.

Even though the PC 1 explained $85 \%$ of the variance, whereas the PC 2 explains only 13\% of the variance, the combination of the two components describes the two most important parameters: wood fibre and leather content. The loadings of the PCs provide information between each of wave numbers and the corresponding score plot of the principle components (Figure 5).

The loadings of the PC 1 show high positive values for the wave numbers around 5110 and $4562 \mathrm{~cm}^{-1}$, which represent protein vibrations. In the loadings for PC 2, contributions

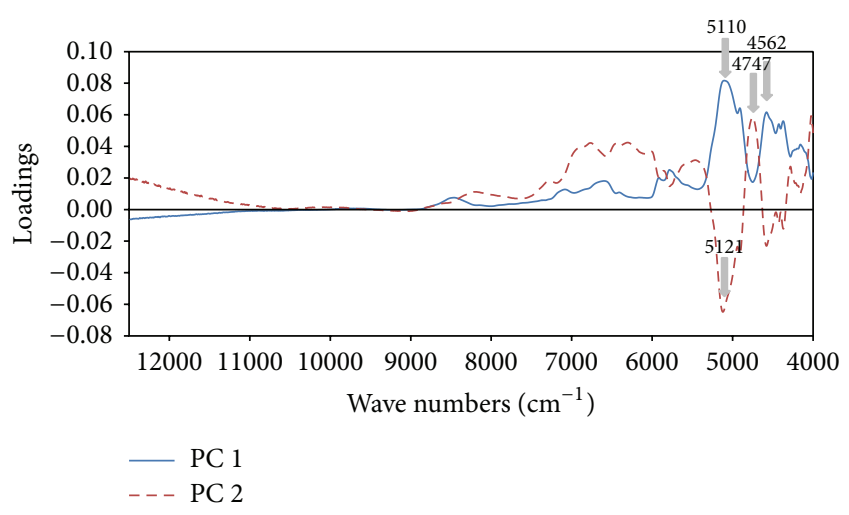

FIGURE 5: Loadings of the first two principal components (PCs) of near infrared spectra of various wood fibre leather panels.

of the wood fibres (e.g., cellulose) derived bands can be observed at band around the wave number $4747 \mathrm{~cm}^{-1}$, which has the highest positive values of the loadings.

The results of the physical and mechanical properties of various wood leather fibreboards are shown in Table 1. With increasing of the leather amount the values of mechanical properties of the wood leather boards were decreased. This phenomenon can be determined for various thicknesses of the wood leather fibreboards. All these results are consistent with the detailed analysis of mechanical properties by Solt et al. [19].

For the PLSR models the NIR data were pretreated by using the second derivative (15 smoothing points). A full cross-validation was performed for every sample. For wood leather fibreboard samples $(n=18)$, the coefficient of determination $\left(R^{2}\right)$ was $77.35 \%$ and the RMSECV was $50.3 \%$ with two principle components (PCs). PLSR models for the bending strength (MOR) of the fibreboard were also calculated with 18 samples, resulting in $R^{2}=93.55 \%$ and RMSECV $=1.7 \%$ with two PCs. Figure 6 shows the measured versus the predicted density of various wood leather fibreboards. The sample amount was small and varied for the different material properties. However, with these results it seems that the FT-NIR spectroscopy is able to estimate the physical and mechanical properties (e.g., bending strength).

The relationship between the mechanical properties and the FT-NIR spectra demands further consideration. The physical and mechanical features of the wood fibre leather composite samples depend on the leather content of the fibreboards. The geometric form of leather particles is not to be compared with wood fibres. Therefore, the distribution of the leather particles is not homogeneous [23]. There are some areas with bigger leather accumulations. Simultaneously, the leather particles can fill in the void of the fibreboard [21]. These phenomena have been taken into account by the use of $4 \mathrm{~mm}$ measurement area of the NIR spectrometer. With changing leather contents the material properties of the fibreboards composite are also modified. Therefore, the leather particles are not only an additive of the wood based boards and can be used for new material resources for wood based panel industry. 
TABLE 1: Estimated mean and standard deviation (SD) of the physical and mechanical properties of the wood leather fibreboards with different leather types ( $w w$ and $w b$ ) and various ratios of wood fibre and leather.

\begin{tabular}{|c|c|c|c|c|c|c|}
\hline \multicolumn{3}{|c|}{ Composition ${ }^{1}$ of the panel } & \multirow{2}{*}{ Thickness (mm) } & \multirow{2}{*}{ Density $\left(\mathrm{kg} / \mathrm{m}^{3}\right)$} & \multirow{2}{*}{$\operatorname{MOE}^{*}\left(\mathrm{~N} / \mathrm{mm}^{2}\right)$} & \multirow{2}{*}{$\operatorname{MOR}^{\#}\left(\mathrm{~N} / \mathrm{mm}^{2}\right)$} \\
\hline Wood (\%) & ww leather $(\%)$ & wb leather $(\%)$ & & & & \\
\hline 66.6 & 33.3 & - & 8 & $807(49.9)$ & $1997.53(148.30)$ & $23.32(1.66)$ \\
\hline 66.6 & 33.3 & - & 12 & $854(31.4)$ & $1779.72(120.77)$ & $17.11(1.79)$ \\
\hline 66.6 & 33.3 & - & 16 & $767(39.1)$ & $1721.00(156.89)$ & $17.14(2.03)$ \\
\hline 66.6 & 33.3 & - & 20 & $764(50.5)$ & $1627.89(195.98)$ & $15.47(2.35)$ \\
\hline 33.3 & 66.6 & - & 8 & $829(27.7)$ & $1178.70(95.74)$ & $13.00(1.10)$ \\
\hline 33.3 & 66.6 & - & 12 & $890(29.3)$ & $1151.01(83.25)$ & $13.33(0.89)$ \\
\hline 33.3 & 66.6 & - & 16 & $835(34.0)$ & $1278.56(127.11)$ & $13.80(1.35)$ \\
\hline- & 100 & - & 8 & $722(24.3)$ & $539.00(88.67)$ & $6.35(0.94)$ \\
\hline - & 100 & - & 12 & $935(59.1)$ & $1099.31(237.85)$ & $9.35(1.76)$ \\
\hline - & 100 & - & 16 & $956(63.7)$ & 908.67 (160.08) & $10.67(1.93)$ \\
\hline- & 100 & - & 20 & $951(59.0)$ & $816.53(156.04)$ & $10.30(1.98)$ \\
\hline 66.6 & - & 33.3 & 12 & $772(90.0)$ & $1513.00(349.01)$ & $14.57(3.42)$ \\
\hline 66.6 & - & 33.3 & 16 & $703(60.5)$ & $1577.00(98.86)$ & $11.80(0.87)$ \\
\hline 66.6 & - & 33.3 & 20 & $694(77.7)$ & $1488.00(189.81)$ & $15.15(1.82)$ \\
\hline 33.3 & - & 66.6 & 12 & $828(30.4)$ & $1142.00(277.49)$ & $12.59(2.86)$ \\
\hline 33.3 & - & 66.6 & 16 & 777 (79.6) & $1122.00(251.38)$ & $11.80(0.87)$ \\
\hline 33.3 & - & 66.6 & 20 & $725(34.5)$ & $938.00(208.01)$ & $9.72(2.01)$ \\
\hline
\end{tabular}

${ }_{1}^{1} 10 \%$ UF adhesive content in every fibreboard.

${ }^{*}$ Modulus of elasticity (standard deviation).

"Modulus of rupture/bending strength (standard deviation).

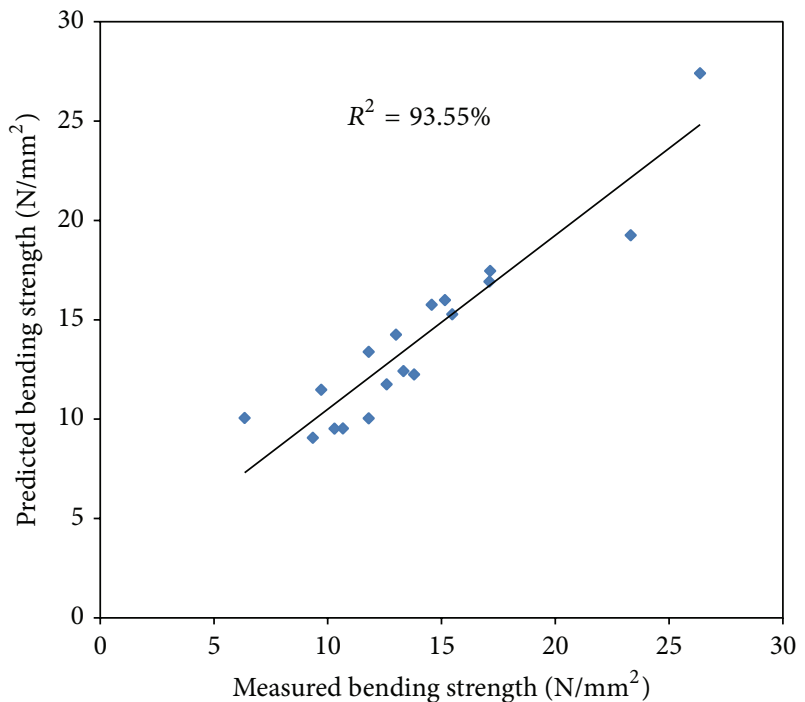

FIGURE 6: Predicted versus measured values of the PLSR model to estimate the bending strength with the FT-NIR data.

\section{Conclusions}

Based on these results of this study, NIR spectroscopy can be used to distinguish wood fibres from different types of leather shavings (wet white and wet blue). These differences can be also observed of the wood leather fibreboard samples. The score plot from the PCA depicts a possible classification into various amounts of leather contents of the fibreboards. Moreover, the PLSR models for the prediction of the physical and mechanical properties were successfully developed. These results demonstrate that a classification of fibreboard composite and the estimation of density as well as bending strength features are possible with fast, nondestructive measurement methods. The methods may serve a basis to establish guidelines for quality assurance control systems of this new engineered wood leather composite fibreboard. These findings provide a basis for further efforts in the upscale from laboratory to industrial conditions for consumer applications.

\section{Conflict of Interests}

The authors declare that there is no conflict of interests regarding the publication of this paper.

\section{Acknowledgment}

The authors gratefully acknowledge the support of the Austrian Research Promotion Agency (FFG) in Vienna under Grant no. 836988.

\section{References}

[1] M. C. Barbu, M. Irle, and R. Reh, "Wood-based composites," in Research Developments in Wood Engineering and Technology, A. Aguilera and P. Davim, Eds., chapter 1, pp. 1-45, IGI Global. Engineering Science Reference, 2014.

[2] M. C. Barbu, R. Reh, and A. Dönmez-Cavdar, "Lignocellulosic composites," in Research Developments in Wood Engineering and Technology, A. Aguilera and P. Davim, Eds., chapter 8, pp. 281319, IGI Global, 2014. 
[3] H. J. Deppe and K. Ernst, MDF-Mitteldichte Faserplatten, DRW Verlag Weinbrenner $\mathrm{GmbH} \& \mathrm{Co}$, Leinfelden-Echterdingen, Germany, 1996.

[4] G. Han, K. Umemura, M. Zhang, T. Honda, and S. Kawai, "Development of high-performance UF-bonded reed and wheat straw medium-density fiberboard," Journal of Wood Science, vol. 47, no. 5, pp. 350-355, 2001.

[5] S. Halvarsson, H. Edlund, and M. Norgren, "Manufacture of non-resin wheat straw fibreboards," Industrial Crops and Products, vol. 29, no. 2-3, pp. 437-445, 2009.

[6] S. Halvarsson, H. Edlund, and M. Norgren, "Properties of medium-density fibreboard (MDF) based on wheat straw and melamine modified urea formaldehyde (UMF) resin," Industrial Crops and Products, vol. 28, no. 1, pp. 37-46, 2008.

[7] J. E. G. Van Dam, M. J. A. Van Den Oever, and E. R. P. Keijsers, "Production process for high density high performance binderless boards from whole coconut husk," Industrial Crops and Products, vol. 20, no. 1, pp. 97-101, 2004.

[8] R. Glowacki, M. C. Barbu, J. Van Wijck, and P. Chaowana, "The use of coconut husk in high pressure laminate production," Journal of Tropical Forest Science, vol. 24, no. 1, pp. 27-36, 2012.

[9] G. Quintana, J. Velásquez, S. Betancourt, and P. Gañán, “Binderless fiberboard from steam exploded banana bunch," Industrial Crops and Products, vol. 29, no. 1, pp. 60-66, 2009.

[10] S. Hiziroglu, S. Jarusombuti, P. Bauchongkol, and V. Fueangvivat, "Overlaying properties of fiberboard manufactured from bamboo and rice straw," Industrial Crops and Products, vol. 28, no. 1, pp. 107-111, 2008.

[11] J. Kanagaraj, K. C. Velappan, N. K. Chandra Babu, and S. Sadulla, "Solid wastes generation in the leather industry and its utilization for cleaner environment," Journal of Scientific \& Industrial Research, vol. 65, no. 7, pp. 541-548, 2006.

[12] S. Lee, T. F. Shupe, and C. Y. Hse, "Mechanical and physical properties of agro-based fiberboard," Holz als Roh- und Werkstoff, vol. 64, no. 1, pp. 74-79, 2006.

[13] J. E. Winandy, J. H. Muehl, J. A. Glaeser, and W. Schmidt, "Chicken feather fiber as an additive in MDF composites," Journal of Natural Fibers, vol. 4, no. 1, pp. 35-48, 2007.

[14] A. Marcilla, A. N. García, M. León, P. Martínez, and E. Bañón, "Analytical pyrolysis as a method to characterize tannery wastes," Industrial and Engineering Chemistry Research, vol. 50, no. 15, pp. 8994-9002, 2011.

[15] LMC International, "Global supply of hides and skins," in Pocket Book for Leather Technologists, BASF, Ludwigshafen, Germany, 2007.

[16] A. Marcilla, A. N. García, M. León, P. Martínez, and E. Bañón, "Analytical pyrolysis as a method to characterize tannery wastes," Industrial \& Engineering Chemistry Research, vol. 50, no. 15, pp. 8994-9002, 2011.

[17] G. Lackinger, “Composite body," Patent no. EP 2135892 A2, 2009.

[18] A. Rindler, P. Solt, T. Schnabel, and M. C. Barbu, "Comparison between HB and HDF made from waste leather," in Proceedings of the PTFBPI Conference, pp. 332-340, Salzburg University of Applied Sciences, Kuchl, Austria, 2014.

[19] P. Solt, A. Rindler, T. Schnabel, M. C. Barbu, and A. Petutschnigg, "High-density composite panel based on wood fibres and leather shavings. Study of mechanical properties," Holztechnologie, vol. 56, pp. 19-24, 2015 (German).

[20] P. Solt, A. Rindler, T. Schnabel, and M. C. Barbu, "The use of waste leather in wood based panels," in Proceedings of the SWST
International Convention, pp. 227-235, Technical University Zvolen, Zvolen, Slovakia, June 2014.

[21] S. Wieland, T. Grünewald, S. Ostrowski et al., "Assessment of mechanical properties of wood-leather panels and the differences in the panel structure by means of X-ray computed tomography," BioResources, vol. 8, no. 1, pp. 818-832, 2013.

[22] T. Grünewald, W. Grigsby, G. Tondi, S. Ostrowski, A. Petutschnigg, and S. Wieland, "Chemical characterization of wood-leather panels by means of ${ }^{13} \mathrm{C}$ NMR spectroscopy," BioResources, vol. 8, no. 2, pp. 2442-2452, 2013.

[23] T. Grünewald, S. Ostrowski, A. Petutschnigg, M. Musso, and S. Wieland, "Structural analysis of wood-leather panels by Raman spectroscopy," BioResources, vol. 7, no. 2, pp. 1431-1439, 2012.

[24] G. Tondi, T. Grünewald, A. Petutschnigg, and T. Schnabel, "ATR FT-IR mapping of leather-fibres panels," Journal of Applied Spectroscopy, vol. 81, pp. 1078-1080, 2015.

[25] E. Dolezel-Horwath, T. Hutter, R. Kessler, and R. Wimmer, "Feedback and feedforward control of wet-processed hardboard production using spectroscopy and chemometric modelling," Analytica Chimica Acta, vol. 544, no. 1-2, pp. 47-59, 2005.

[26] S. Tsuchikawa, "A review of recent near infrared research for wood and paper," Applied Spectroscopy Reviews, vol. 42, no. 1, pp. 43-71, 2007.

[27] OENorm EN 319, "Wood-based panels-determination of modulus of elasticity in bending and bending strength," 2005.

[28] OENorm EN 326-1, "Wood-based panels-sampling, cutting and inspection-part 1: sampling and cutting of test pieces and expression of test results," 2005.

[29] K. H. Esbensen, Multivariate Data Analysis_In Practice. An Introduction to Multivariate Data Analysis and Experimental Design, CAMO Press, Oslo, Norway, 2002.

[30] W. Kessler, Multivariate Datenanalyse für die Pharma-, Bio- und Prozessanalytik, Wiley-VCH, Weinheim, Germany, 2006.

[31] S. J. Shenk, J. Workman, and O. M. Westerhaus, "Application of NIR spectroscopy to agricultural products," in Handbook of Near-Infrared Analysis, A. D. Burns and W. E. Ciurczak, Eds., pp. 419-474, Marcel Dekker, 2001.

[32] M. Schwanninger, J. C. Rodrigues, and K. Fackler, "A review of band assignments in near infrared spectra of wood and wood components," Journal of Near Infrared Spectroscopy, vol. 19, no. 5, pp. 287-308, 2011. 

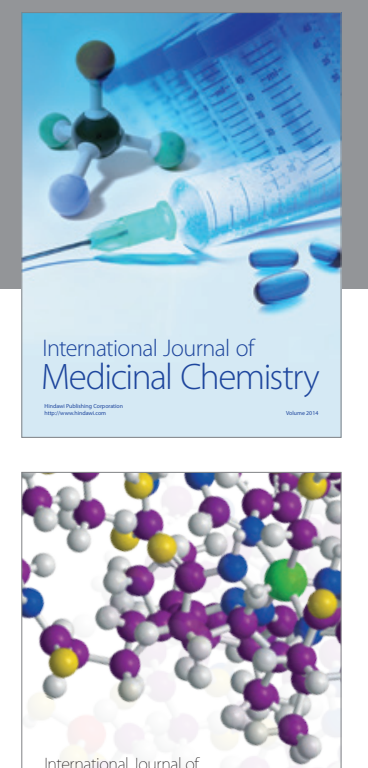

\section{Carbohydrate} Chemistry

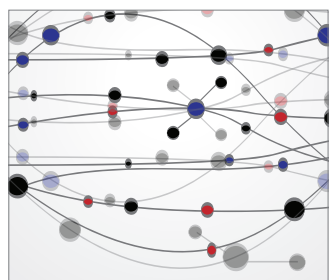

The Scientific World Journal
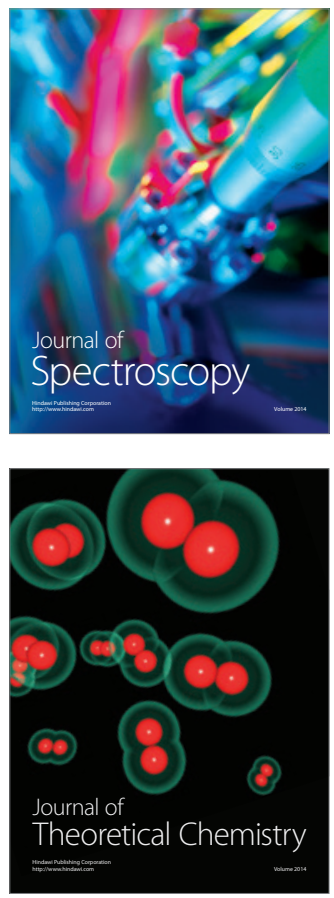
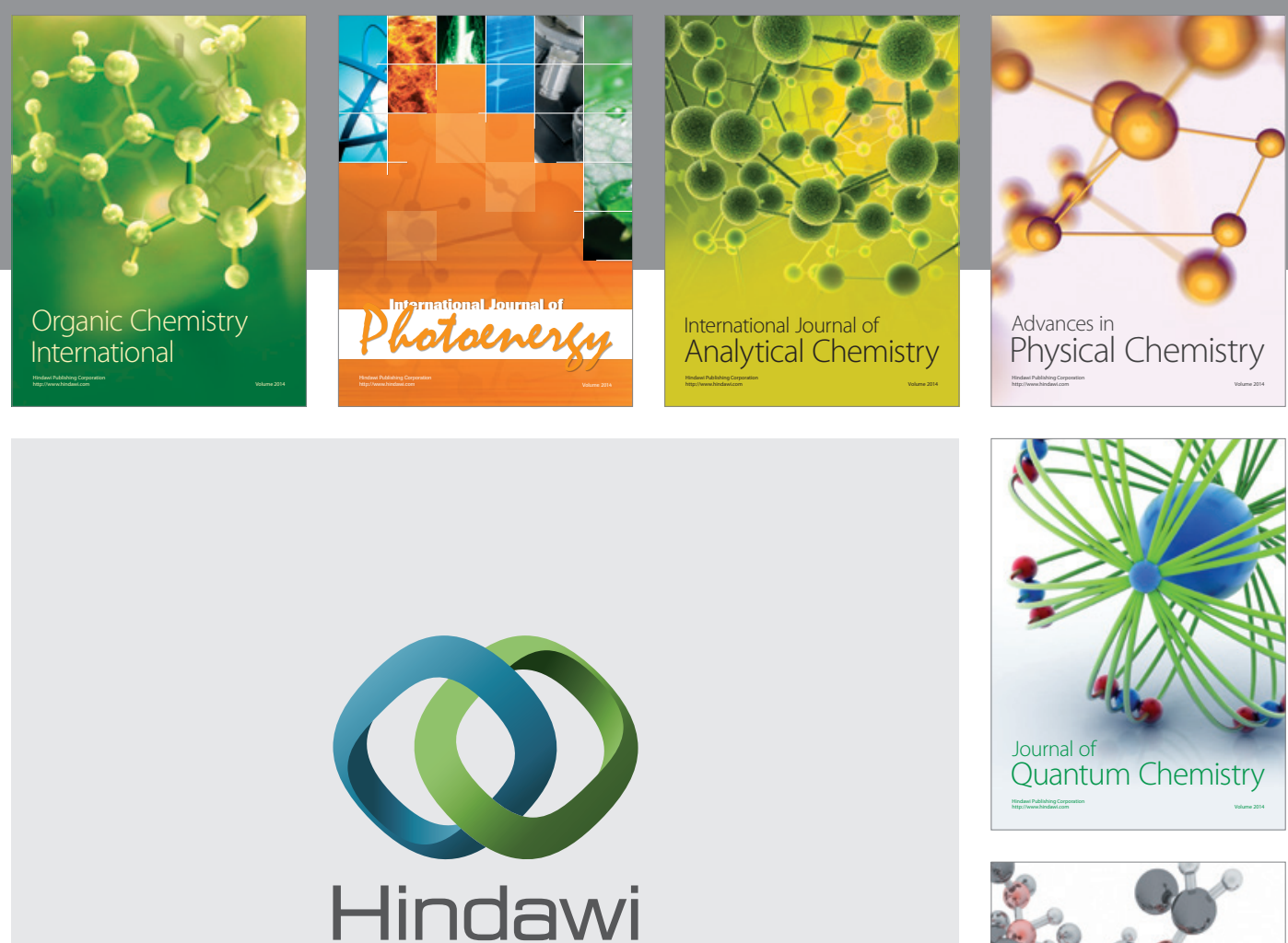

Submit your manuscripts at

http://www.hindawi.com

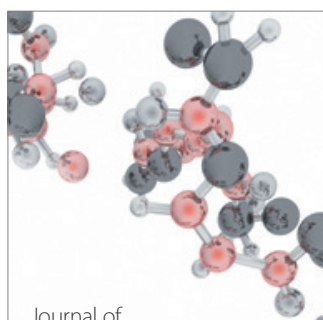

Analytical Methods

in Chemistry

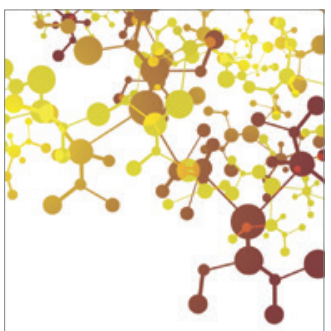

Journal of

Applied Chemistry

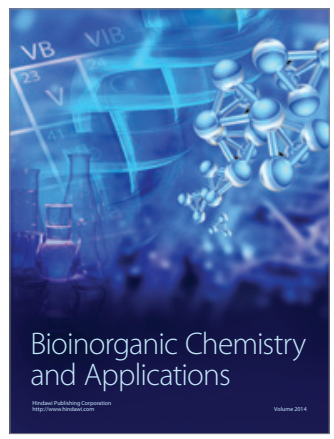

Inorganic Chemistry
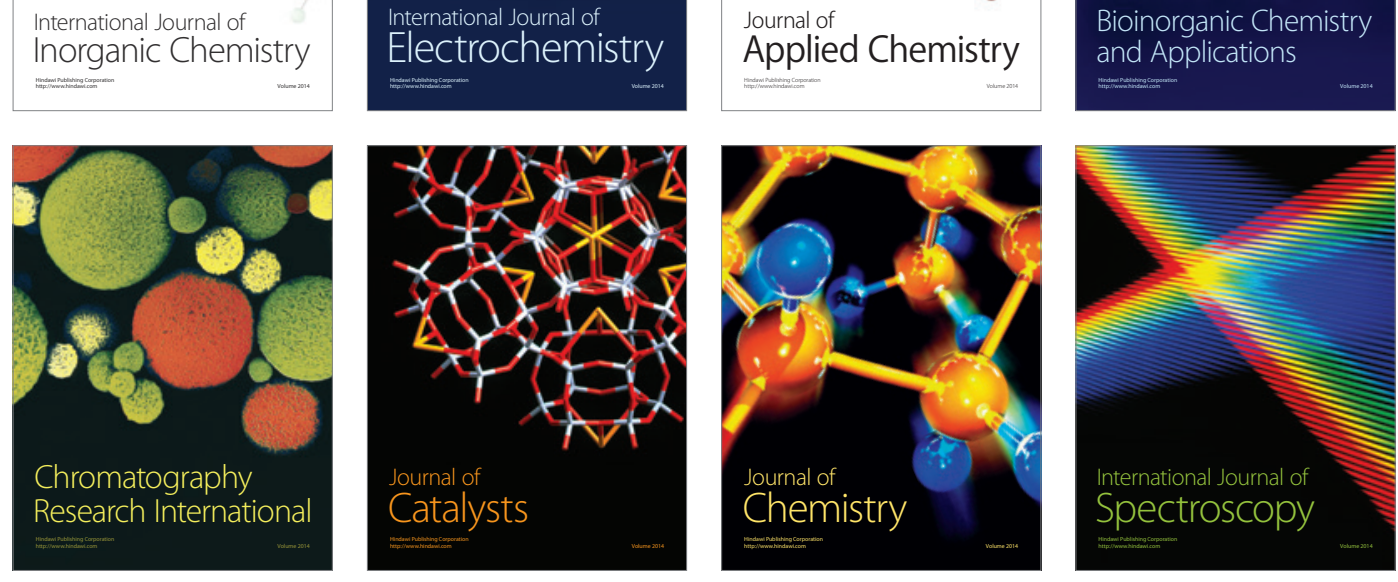